\title{
Discussion on the Graduate Cultivation Mode of Innovative and Entrepreneurial Full-time Professional Degree
}

\author{
Huaqiang Zhang ${ }^{1}$, Hongbo Shi ${ }^{2}$, Hannan Fang ${ }^{1}$ \\ ${ }^{1}$ Department of Postgraduate, Harbin Institute of Technology at Weihai, Weihai 264209, China \\ ${ }^{2}$ School of Economics and Management, Harbin Institute of Technology at Weihai, Weihai 264209, China \\ zhq0027@126.com,rand@sina.com,fhnzfz@sina.com
}

\begin{abstract}
According to the requirement of classification cultivation mode and the features of cultivating the applied professional degree for graduate students, an innovative and entrepreneurial full-time professional degree cultivation mode is discussed from the aspects of training objectives, training program and teaching and so on. It also proposes a series of assurance measures such as enforcing the supervisor group and the training platform, teaching innovative and entrepreneurial courses. And all of these measures reflect the character of the applied postgraduates training and improve the management system.
\end{abstract}

Index Terms - Full-time Professional Degree; Innovation and Entrepreneur; Cultivation Mode

\section{Introduction}

Since the 1978 restoration of graduate enrollment, the quality and quantity of graduate cultivation have comprehensively improving, postgraduate education has a rapid momentum of development. In the past decade the scale of postgraduate students increased from 300,000 to 1.3 million. In order to adapt to the new situation, in 2009 the Ministry of education proposed full-time professional degree graduate training program, opened a reform precedent of postgraduate classification training mode, then the transition went from a single academic training type to the academic type and application type, accelerated the high-level practical talent's cultivation [1].

Full-time professional degree graduate cultivation in China was in the initial stage, in the aspect of training scheme, curriculum and innovative practice need to be continuously explored and improved. By the end of 2009, our professional degree category was 19, the high-level universities were the first universities to recruit the full-time professional degree graduate [2]. The training experience of full-time professional degree graduate students in many years told us: the cultivation of applied talents should combine with actual practice and service demand.

As a quality supervision and security system in the process of graduate cultivation, education management plays a significant role in innovation and development of graduate students education and improvement of academic dissertations. Faced with the difference between academic and practical graduate students cultivation models, graduate students education administration should make normative documents which cater to development of colleges and insist on tracking management which means tasks being shared, inspected, supervised, feedback and adjusted as well as human-oriented management and service conception.

\section{The Significance of Professional Degree Graduate Cultivation}

Postgraduate education experience a transition from a single culture model to the on-the-job master of engineering cultivation and full-time professional degree graduate cultivation models in china. As a new mode of training, professional degree is the inevitable trend to the reform of the system of postgraduate training.

A. The necessity of Society and economic construction

Thirty years of reform and opening up, with the rise of China economy, Chinese economy status were so far ahead. In 2010, China has become the second largest economy in the world. The rapid growth of China's economy benefited from many factors, where the Made-in-China changed into Createdin-China was the main way to convert the mode of economic development, the high-level applied talents cultivation was the lifeblood of Created-in-China. The sustainable development of were promoted through the technical innovation. The sustainable development of Created-in-China cannot be separated with technical revolution. The national "Twelfth Five Year" plan proposed the task of innovation country construction and considered enhancing the independent innovation capability as the strategic basis for the development of science and technology, take the road of China characteristic independent innovation, urgently needed a large number of the high-level talents who had the innovative ability, entrepreneurial ability and practical ability.

B. The necessity of multi-level graduate cultivation

To adapt to the social development, postgraduate education should update the concept, arrange reasonable, service demand and improve quality. Western countries started early in training applied talents. Such as, American's

\footnotetext{
* This work is partially supported by the foundation of ministry of education humanities and social sciences research project (13JDGC014) and the foundation of Shandong province higher school teaching reform project (2012166) to Huaqiang Zhang.
} 
professional degree graduate education is the most developed, having the master and $\mathrm{PhD}$ two levels [3]. The British universities also train postgraduate according to the research type and professional type two directions.

Ninety years ago, the model of graduate students cultivation in China is single, belongs to elitist education. In the early ninety, we increased the postgraduate on-the-job engineering training types, combining training and industry. At the end of the ninety's, with the increasing of the demand for talents and the higher education popularization, the voices of full-time professional degree graduate cultivation in China become increasingly loud, this kind of cultivation mode enriched and developed the traditional graduate education connotation.

\section{The necessity of Modern Talents cultivation}

Talent is the person who has professional knowledge or skills, creative and make a contribution to society. The modern concept of talent is the view of talent under the conditions of the market economy, stressing the comprehensive quality and ability of talent, promoting talent competition and incentive mechanism, pursuing efficiency and effectiveness, highlighting individual achievement and contribution and meeting the requirement of the market economy.

The professional degree is to culture modern talent who has advanced technology, product development, production technology innovation and operation management and other aspects, facing the high-tech enterprises, construction and management departments. Professional degree graduate training faced the social demand, production and innovation, emphasizing the spirit of innovation and entrepreneurship, complying with the requirements of modern talent view.

\section{The Features of Professional Degree Graduate Cultivation}

Professional degree graduate cultivation as a new training model of professional degree graduate, emphasized on graduate should have an unique method of knowledge acquisition, thinking ability and creative development etc. Especially the full-time professional degree graduate training, needed to research and develop the training program and evaluation standards combining the industry development needs, reflecting the graduate education should have high starting point of cultivation, high standard of cultivation quality and high requirements of innovative ability. The paper based on the Control Engineering degree graduate cultivation as a case, discussing the cultivation measures of innovative and entrepreneurial engineering master.

Control Engineering has played an important role in industrial production and social life since the industrial revolution. With the progress of science and technology, Control Engineering has been enriched and developed in the theory and practice, throughout the course of development, it formed the following characteristics [4]:

\section{A. The practicality}

Practical problem in social production is the basic power of Control Engineering's development and widespread use. The original automatic control system was a speed control system of the steam engine in the industrial revolution period, which was a control device to solve the problem of oscillation. The development of steam adjusting device introduced the study of the stability of the system. In the $1860 \mathrm{~s}$, the rapid development of space technology promoted the creation of modern control theory. So, practice is the source of control theory development.

\section{B. The system}

Control Engineering always analyzed the various phenomena from the "system" and achieved a variety of goals. Control was all accomplished by a closed loop system, and this system consists of sensor, controller, actuator and control object etc., they complete the control task by the coordination.

\section{The crossover}

As the core of "system" science, Control Engineering and mathematics, computer, communication, network, electronic technology and related fields has always maintained close relations of crossover and integration. The control theory corresponded the software algorithm of the control system was based on linear algebra, mathematics of complex variable function and functional analysis etc.; and the realization of the control system was closely related to the development of computer, power electronics technology.

\section{The modernity}

Whether theorists or engineers, people always apply the most advanced and effective ideas and techniques to the Control Engineering. Such as: the control and management integration, information flow and material energy flow interaction, complex system research and application all showed the strong characteristics of the times. Information era gave birth to the network control and the driven control based on data. Setting the Control Engineering degree graduate education accorded with national policy training talents as well as the characteristics of this subject's development and the social needs. Practice and system in Control Engineering fitted applied talent cultivation, at the same time, crossover and modernity suited the innovative and entrepreneurial talents cultivation.

"Practice is the sole criteria for testing truth", the graduate student can improve their ability to integrate theory with practice and cultivate team consciousness by participating in practice. So teachers should create enough practice opportunities for graduate students to be involved in specific research projects. In practice, graduate students should improve their professional quality, practice ability and cultivate innovative spirit of striving [5].

The supervisors should take part in the postgraduate innovative education reform actively. Combined with the connotation of the discipline construction, some innovation practice base must be build for full-time professional degree applied graduate student practice ability; Pay attention to investigation and study, from the policy and practice to 
explore the academic and applied process of graduate education essence, classified reasonable training plan.

\section{The Measures of Professional Degree Graduate Cultivation}

\section{A. "Double Tutorial System"}

At present, the graduate student education is mostly single-teacher training mode, and interdisciplinary subjects have become widespread. Improving the cultivation of single mode has become the inevitable trend of graduate education reform.

Postgraduate education of Control Engineering is a kind of applied education which is based on the postgraduate education of Control Science and Engineering. Comparing with Academic postgraduate, it pays more attention to practical. Most traditional education concentrates heavily on academic theory while there are few subjects being connected to the engineering practice.

The young professors have few experiences on engineering practice. Young doctors are being professors and teaching at universities after graduation leading to not closely related to the factories. To fill the gap that the lacking of practice experience of university teachers, we advocate dual professors, which educates students not through university tutors but also the senior experts from different companies. The professors from university focus on academic theory while the professors from companies focus on real project. Professors from companies having higher academic qualification and abundant experience on practice are chosen by university committee.

The Control Engineering of our school has 8 professors coming from different companies such as automation institute of Shan Dong province, Shen Yang automation institute of The Chinese Academy of Sciences and the company of Qing Dao Gao Xiao. The researches of postgraduate involve underwater robot controlling, aerospace turntable control, satellite attitude control and tire control. These different researching fields provide topics which feature of the time to the postgraduate.

Exploring dual-supervisor training mode which is beneficial to widening the graduate student's field of vision will promote the all-round development of graduate education.

\section{B. The innovation practice course}

The courses of postgraduate have effect on the educational quality of postgraduate directly. According to the goal of education the courses of full-time postgraduate should be practical and comprehensive. In order to cultivate innovative postgraduates, 2 ways have been implemented on the plan of courses. Firstly all professional courses must be directed by actual application, with the target to demand of career, as well as improving comprehensive literacy. All the courses combine theory with actual application and emphasize case analysis and practical research. Because of focusing on researching with team, case analysis, researching on site, and simulation training during postgraduate teaching, we promote the revolution of teaching and curriculum-building. Secondly 4 score have been put into innovative practice course. Practice course could be the software or the hardware as well as working at companies and institutes. Postgraduate should research during project, analysis data, design system, test system, submit curse reports, practice data and analysis design results etc.

\section{The entrepreneurial knowledge module}

Full-time professional degree graduate education not only let the students grasp the deep professional knowledge and skills, but also possess comprehensive management ability, and become entrepreneurial ability of senior management personnel. After graduation, professional degree graduate students will directly face to high-tech enterprise and management, and become the main force of innovative products and business management in the future. Under market-oriented economy, graduate training scheme will be added two entrepreneurial knowledge modules. One is to systematically study economic management knowledge, through the corresponding courses. Set up basic principles of management and economics, enhancing the ability of organization management and adapting to the economic development of professional degree graduate, improve the knowledge system required to cultivate the senior professional management personnel. Another way is to open entrepreneur BBS, and show successful business case. Entrepreneurs can be a leader of a large enterprise, or a small and medium-sized enterprise entrepreneur. They can transfer their successful experience by sharing the growing experience, the conditions of entrepreneurial quality, and entrepreneurship. In the field of control engineering, the subject has a character of system and crossover itself, this kind of professional degree graduate fit to the entrepreneurial leadership positions. The entrepreneurship education enhances knowledge of the professional degree graduate student, and fully embodies that the characteristics of graduate education is practical application.

\section{Problems and Solutions}

Full-time Control Engineering professional degree graduate education have been in existence only for a few years, a lot of rules and regulations are still need to develop and perfect. The requirements of full-time professional degree graduate training in China should achieve the high starting point, high quality standards and the high ability to innovate and practice. But there are still some problems and difficulties in the process of cultivation.

First of all, teachers and students did not have enough understanding to the professional degree graduate education. The common understanding is the professional degree students have a lower level than academic graduate, which is not recognized by society, then there are more candidates for academic graduate students instead of professional degree graduate students, resulting in the tutor teach the professional degree graduate are lack of confidence. Although it is the same treatment and policy in the proportion and selection of graduates scholarship, but some employers still have treat two types of graduates differently. So, tutor should adjust the 
direction of training timely, fully embodying the characteristic of professional degree graduate training.

Secondly, the characteristics of the professional degree graduate training scheme are not obvious. It needed the different cultivation plans for these two type students. But, the single education mode of curriculum have been existed for a long time, it is difficult to reflect the characteristics of applied postgraduate education. The school have sat up a platform for training a number of innovative talents through the "985 Project" and the local construction projects, mobilizing the enthusiasm, making more teachers plunge into the graduate teaching reform and practice, constructing a curriculum system to improve the innovation and entrepreneur ability of the students.

In addition, the evaluation system of the professional degree graduate's thesis is not perfect. For thesis in different orientation, should be different [6]. At present, in our school require the business mentor take part in the review and evaluation of the professional degree student's paper, to take full account of the applied professional degree thesis should focus on practice and innovation. But the final review department of the Graduate Thesis should be the same Academic Degrees Committee. So we should give a evaluation standard to the different thesis, making the tutor and the Academic Degrees Committee evaluate the quality of papers in a unified standard.

In conclusion, Dual-supervisor cultivation model will integrate scientific research resources among mentors and cultivate innovative graduate student with high quality. Combined with the control engineering professional degree graduate's cultivation, do some reform and attempt in knowledge structure, curriculum characteristic and evaluation standards. In the face of the demand for high-level innovative talents, it is worth studying deeply how to train qualified personnel for the education workers.

\section{Acknowledgment}

The authors thank all the support foundation of ministry of education humanities and social sciences research project
(13JDGC014), the foundation of Shandong province higher school teaching reform project (2012166) and the foundation of Shandong province higher school high-quality curriculum (2013BK044), which enabled the achievement of the mentioned research results.

\section{References}

[1] Zhang Liping, Kong Hanbing, Chen Zichen, "International Progress ofMaster of Engineering Education," Academic Degrees and Graduate Education, no. 2, pp. 21-28, February 2012.

[2] DING Xuemei, ZHEN Liang, SONG Ping, YANG Lianmao, WEI Xianyu, "Reform the Cultivation Mode and Frame the Cultivation System," Academic Degrees and Graduate Education, vol. 2, no. 1, pp. 1-4, February 2010.

[3] WANG Yu, KANG Ni, LIU Huiqin, "On the Cultivation of Full-time Engineering Masters," Academic Degrees and Graduate Education, vol. 2, no. 2, pp. 5-7, February 2010

[4] CHEN Xiao-ping, LUO Wen-jian, "A Study of the Practicum and Innovation Training System Based on Robot Experiments," Journal of Graduate Education, no. 3, pp. 48-52, June 2011.

[5] Zhang Huaqiang, Wang Xinsheng, Fang Hannan, "Position and Role of Supervisors in Graduate Education Administration," Journal of Harbin Institute of Technology (Social Sciences Edition), vol. 14 (Supplement 2), pp. 19-21, December 2012.

[6] Zeng Fang, Cao Min, Tang Yan, "The construction of multi-tutor cultivation model," Wuhan Institute of Technology (society \& science), vol. 21, no. 2, pp. 264-267, February 2008.

[7] ZHEN Liang, KANG Jun, YING Shuang, "Construction of QualityEvaluation and Assurance System for Professional Master's Degree Programs," Journal of Graduate Education, no. 6, pp. 52-55, December 2012.

[8] JIAN Jie, XI Haifeng, "To Build Collaboratively Innovational Postgraduate Education System," Journal of Science and Education, no. 10, pp. 163-165, October 2012.

[9] HU Ying, YANG Xue, "Quality Management and Quality Evaluation for Full Time Professional Graduate Education," Journal of Graduate Education, no. 2, pp. 66-70, April 2012.

[10] ZHA Zhen-gao, KUANG Ying-zhi, DING Huai, "Comprehensive Quality Control System Construction for Full time Professional Degree Postgraduates," Journal of China University of Mining \& Technology(Social Sciences), no. 4, pp. 82-86, April 2010.

[11] ZHANG Xiao-yan, SONG Mao-qiang, "Process Management and Quality Control for Professional Degree These Prepared by Full-Time Master's Students," Journal of Graduate Education, no. 3, pp. 69-72, June 2011. 